Essay

\title{
Ethical Concerns in the Rise of Co-Authorship and Its Role as a Proxy of Research Collaborations
}

\author{
Sameer Kumar \\ Asia-Europe Institute, University of Malaya, Kuala Lumpur 50603, Malaysia; sameer@um.edu.my; \\ Tel.: +60-3-7967-6929
}

Received: 27 June 2018; Accepted: 14 August 2018; Published: 16 August 2018

\begin{abstract}
Increasing specialization, changes in the institutional incentives for publication, and a host of other reasons have brought about a marked trend towards co-authored articles among researchers. These changes have impacted Science and Technology (S\&T) policies worldwide. Co-authorship is often considered to be a reliable proxy for assessing research collaborations at micro, meso, and macro levels. Although co-authorship in a scholarly publication brings numerous benefits to the participating authors, it has also given rise to issues of publication integrity, such as ghost authorships and honorary authorships. The code of conduct of bodies such as the American Psychological Association (APA) and the International Committee of Medical Journal Editors (ICMJE) make it clear that only those who have significantly contributed to the study should be on the authorship list. Those who have contributed little have to be appropriately "acknowledged" in footnotes or in the acknowledgement section. However, these principles are sometimes transgressed, and a complete solution still remains elusive.
\end{abstract}

Keywords: co-authorship; scholarly publications; research collaborations; ethics; APA; ICMJE

\section{Introduction}

A number of studies have reported an increasing trend of papers with multiple authors in every scientific discipline within and across countries [1]. Price [2] first reported that the proportion of multi-authored research papers in the research literature was rising. Large industrial projects, improvements in communication facilities led by information technology, and the mobility of researchers created fertile ground for researchers to work in groups [2,3]. Price [2] noted that the trend toward co-authorship is 'one of the most violent transitions that can be measured in recent trends of scientific manpower and literature' (p. 89).

Research collaborations bring together researchers to accomplish a research output. Co-authorship in research papers is often considered to be the most verifiable form of research collaboration, and gauging research collaborations has thus become an increasingly active area within Scientometrics. Scientometrics as a field involves "the quantitative methods of the research on the development of science as an informational process" [4]. Vassily V Nalimov coined the word Scientometrics (Naukometriya, in Russian) in the 1960s, and since then it has been used to describe the study of science in terms of its growth, structure, inter-relationships, and productivity [5]. During the 1960s, Derek John de solla Price carried out pioneering work on the quantitative indicators in formulating science policy, with classics such as Science Since Babylon [6], Little Science Big Science [2], and an article in Science on 'Networks of Scientific Papers' [7].

The purpose of this essay is to assess co-authorship in scientific literature: its rise, its consideration as a proxy of research collaboration, and its ethical concerns. Authorship is not only a merit but also a responsibility [8]. Hence, authorship credits deserve focused attention. Our effort here is not to suggest ethical best practices, as there are already prescribed guidelines by associations such as the 
American Psychological Association (APA), the International Committee of Medical Journal Editors (ICMJE), or Committee on Publication Ethics (COPE), but to discuss and highlight the ethical issues that still occur despite these guidelines being in place.

\section{Rise of Co-Authorship in Scientific Literature}

In the 1940s, the percentage of single-authored papers was as high as $91 \%$, declining to $66 \%$ in the 1990s. Grossman [9] examined co-authorship in mathematical research and showed a similar rise in papers with multiple authors from the 1940s through the 1990s. His research also found a steady rise in the number of papers with two and three authors, proving increased collaboration among mathematicians in recent years compared to the 1940s. While examining scientific authorship on Chagas disease, Gonzalez-Alcaide et al. [10] noted that collaboration among researchers had increased dramatically. Miro et al. [11] identified a similar increase in the collaboration patterns of Spanish emergency physicians in the period between 2005 and 2009. The growth in the number of co-authored publications is being reported across various disciplines and different parts of the globe. Sooryamoorthy [12] found that the number of co-authored publications has grown in South African engineering research, while the number of papers with a single author decreased. Co-authorship differs between the physical sciences and the social sciences due to the experimental nature of the physical sciences. However, recent trends in the rise of large-scale data collection in social sciences replicate that of large labs, requiring the collaboration of multiple researchers in a way similar to that of physical sciences [13]. Some areas in social sciences, such as social anthropology, may be less co-authored compared to other areas, such as economics, where specialization and the ease of bringing a new person onto the research team instead of learning new material makes co-authorship an easier option [13]. Nonetheless, co-authorship in the social sciences also has seen a steady increase [14].

\section{Co-Authorship as a Proxy of Research Collaborations}

Co-authorship in research articles is considered to be a reliable proxy of research collaborations. Sonnenwald [1] defines research collaboration as "human behaviour among two or more scientists that facilitates the sharing of meaning and completion of tasks with respect to a mutually shared superordinate goal and which takes place in social contexts" (p. 3). Subramanyam [15] puts this more succinctly by defining research collaboration as " ... a joint work on a project of two of more investigators who contribute resources and effort-both intellectual and physical" (p. 34). This definition emphasizes a few important aspects of research collaboration. First, it is a joint work between two or more researchers, which mainly involves the sharing of resources or intellectual expertise. Second, research collaboration has a goal. The goal may be to bring about a definite product in the form of a research article, for instance. It may also have individual goals, such as a PhD scholar or junior scientist wishing to obtain a promotion through the positive outcome of the research [16]. Third, the research takes place in a 'social context'. This last point is crucial, as in most cases, the scientists collaborate with others based on their personal choices.

Beaver [17] and Beaver and Rosen [18] presented a history of research collaboration, starting as early as 1800, when collaboration in papers was a prerogative of French chemists. The study of research collaborations emerged from the larger field of Scientometrics. Hence, an overview of this field would provide a basis for a better understanding of this field. Nonetheless, Katz and Martin [19] and Ponomariov and Boardman [20] have noted a few issues when considering co-authorship in a paper as the only means to evaluate research collaboration. For example, a researcher making a brilliant suggestion over a casual discussion may be more instrumental in shaping the course of research than days of labour-intensive work in the laboratory. In some situations, collaboration between researchers may not end in joint co-authorship of a paper. For example, two researchers may work closely together but may choose to write separate papers to suit their audiences. Furthermore, due to the complex nature of human interactions that take place between researchers over a period of time, the precise nature and magnitude of collaboration cannot be easily determined [15]. 
Heffner [21] took this idea further and divided collaboration broadly into two types: theoretical and technical. In theoretical collaboration, the association is limited to rendering advice, ideas, or criticism, whereas practical collaboration encompasses tangible assistance in a research endeavour. In general, the researchers in 'technical' collaboration are cited in the author list of the journal article, while those who have given 'theoretical' assistance are cited in the acknowledgement section of the journal article. Measuring research collaboration through survey and observation may not be precise. For this reason, the use of co-authorship in journal articles is a more tangible and easier way to determine collaboration.

Katz and Martin [19] noted that one of the greatest benefits of co-authorship in papers is that it is 'invariant and verifiable'. As co-authorship is based primarily on bibliographic records, one should be able to replicate the results given the same datasets. A second advantage is that the scalability of the sample size that could be analysed by this technique could be very large. Therefore, the results should be more statistically significant compared to those of qualitative studies, questionnaire-based studies, or case studies, for instance. Katz and Martin [19] mention a third, and often overlooked, advantage: that these studies are 'non-reactive', meaning their measurement does not affect the collaboration process. However, other researchers have suggested that, although not immediately, the results of bibliometric study may affect the collaborative process over the longer term [19].

\section{Price's Big Science and Little Science and Why They Are Relevant to Co-Authorship}

The Scientometrics discipline uses archival records of scientific communication in the form of citations, addresses, substantive messages (i.e., keywords), and relational information to reconstruct patterns and identify the hidden characteristics of both authors and documents. The works of Kuhn [22] and Price [2], Price and Weber [6], and Price and Beaver [23] provided a link between the philosophical issues of the growth of scientific knowledge and the sociological quest for the production of knowledge. Whereas Kuhn emphasized the relations among authors working within paradigms and the growth of knowledge, Price highlighted the relationship between knowledge growth and document sets [24].

Price [2] referred to larger 'teamwork' research collaboration as 'Big Science' and small group collaboration as 'Little Science'. Big Science is the fallout of the industrial era, where professionalism and increased knowledge brought forward large-scale research [18]. Quantitative work is more likely to be co-authored than non-quantitative work [13]. Considering an example of non-quantitative work, in the humanities, a lonely scholar still manages to produce a fair degree of research literature without the trappings of 'Big Science' [15]. In contrast to small collaborations, where collaboration followed a Poisson distribution, co-authorship in giant collaboration followed a power law. Collaboration grew at a much faster rate after WWII, primarily due to giant collaborations (or teamwork). Governments in various countries have taken initiatives to bring together scientists through collaborative research programs at both national and international levels [25]. These are generally teamwork types of research where the choice of who should be on the team may not necessarily be in the social domain. A formal selection board might be selecting researchers.

One of the characteristics of 'Big Science' is the requirement of massive funding and large labs. Most research within the scope of 'Big Science' is conducted within physical sciences, such as 'high-energy physics', whereas 'Little Science' research is conducted across a wide spectrum of soft sciences, from social sciences to humanities and arts. Beaver [17] even argued that 'Big Science' could be considered as 'collaboration', as it falls outside the purview of researchers associating because of social function. 'Big Science' studies are conducted primarily in the natural sciences or experimental fields, such as science and biomedical fields. In one of the early studies quoted by Garfield [26], the percentage of papers with multiple authors in the social sciences, economics, and sociology was $17-25 \%$, in contrast to $47-81 \%$ in gerontology, psychiatry, psychology, and biochemistry. This scenario is fast-changing, and a large percentage of papers are now co-authored, even in the social sciences. Nonetheless, collaboration with a smaller number of researchers is characteristic of the humanities, social sciences, and theoretical sciences, such as mathematics. 
Thus, co-authorship arrangements may have two aspects: one that involves actual social function, where researchers choose who they would like to work with (or 'Little Science') and 'teamwork' (or 'Big Science'), where a large number of researchers work on a research project but may not be free to select their research partners [3].

\section{Honorary and Ghost Authorships}

In honorary and ghost authorship, the idea of 'significant contribution' is not reflected in the author list. Someone who has contributed little or nothing gets to be an author. Similarly, a ghost author gets no credit for his/her contribution, as he/she is not on the author list.

'Significant contribution' is an important criterion for authorship credit. Bodies such as the APA and ICMJE have well-structured rules for a person to qualify as a co-author of a paper. The primary author assumes responsibility for the publication, makes sure that the data are accurate, that all deserving authors have been credited, and that all authors have given their approval to the final draft, and handles responses to inquiries after the manuscript is published.

The APA Ethical Principles of Psychologists and Code of Conduct [27] specify who can be on the authorship list:

\section{“8.12 Publication Credit}

(a) Psychologists take responsibility and credit, including authorship credit, only for work they have actually performed or to which they have substantially contributed. (See also Standard 8.12b, Publication Credit.)

(b) Principal authorship and other publication credits accurately reflect the relative scientific or professional contributions of the individuals involved, regardless of their relative status. Mere possession of an institutional position, such as department chair, does not justify authorship credit. Minor contributions to the research or to the writing for publications are acknowledged appropriately, such as in footnotes or in an introductory statement.

(c) Except under exceptional circumstances, a student is listed as principal author on any multiple-authored article that is substantially based on the student's doctoral dissertation. Faculty advisors discuss publication credit with students as early as feasible and throughout the research and publication process as appropriate."

The APA code of conduct makes it clear that only those who have significantly contributed to the study can be on the authorship list. Those who have contributed little have to be appropriately 'acknowledged' in footnotes or in the acknowledgement section.

The International Committee of Medical Journal Editors (ICMJE) also has criteria for dealing with authorship issues [28,29]. It requires all four of the following criteria to be met by the researchers [30]:

"The ICMJE recommends that authorship be based on the following 4 criteria:

Substantial contributions to the conception or design of the work; or the acquisition, analysis, or interpretation of data for the work; AND

Drafting the work or revising it critically for important intellectual content; AND Final approval of the version to be published; AND

Agreement to be accountable for all aspects of the work in ensuring that questions related to the accuracy or integrity of any part of the work are appropriately investigated and resolved.

In addition to being accountable for the parts of the work he or she has done, an author should be able to identify which co-authors are responsible for specific other parts of the work. In addition, authors should have confidence in the integrity of the contributions of their co-authors. 
All those designated as authors should meet all four criteria for authorship, and all who meet the four criteria should be identified as authors. Those who do not meet all four criteria should be acknowledged."

However, the issue of who should be the first author can become stormy at times, sometimes needing to be resolved in court [31]. In interviews with Nobel Laureates and comparisons of their name order practices, Zuckerman [32] found that laureates exercise their noblesse oblige by giving more credit to less-eminent co-workers as their eminence grows.

Jabbehdari and Walsh [33] claim that guest and ghost authorship are quite common across fields. Honorary authorship (also termed as 'guest authorship' or 'gift authorship') includes researchers who might not have provided a significant contribution to the paper. Another extreme is ghost authorship, which fails to mention the names of those authors who had merit to be included in the authorship list of the paper. In other words, ghost authors are individuals who have contributed to the paper substantially, but they may not want their names to be revealed or they may have an arrangement to conceal their name from the author list. Honorary authorship and ghost authorships are two extremes of scholarly malaise. One of the first serious discussions of honorary authorship appeared in the case study by Hagstrom [34], in which he found that some publications had author names listed for purely social reasons. In another study, Flanagin et al. [35] received responses from 809 corresponding authors of articles published in three peer-reviewed journals in 1996 and found evidence that 19\% and $11 \%$ of these papers involved honorary and ghost authorship, respectively. In yet another study on Cochrane reviews, Mowatt, et al. [36] found a similar pattern of honorary and ghost authorships. They carried out a web-based, self-administered survey on 577 reviews published in the Cochrane Library and found that 39\% of the reviews had evidence of honorary authors, $9 \%$ had evidence of ghost authors, and $2 \%$ had evidence of both. Wislar et al. [37] conducted a cross-sectional survey of six high-impact biomedical journals and found evidence of honorary and ghost authorship in $21 \%$ of the 896 research articles.

Medical journals stand for accountability, responsibility, and credit [36], and the presence of a substantial proportion of honorary and ghost authorship should indeed be a matter of concern among members of the medical community. However, a comprehensive literature is still lacking on honorary authorship and ghost authorship in the sciences, and even fewer reports exist in the social sciences. Marusic et al. [38] carried out a meta-analysis of 123 studies across disciplines (biomedical and non-biomedical), which showed that a pooled weighted average of $29 \%$ of researchers reported experience (their own or others') with misuse of authorship. The trend of honorary authorships may be growing for many reasons. For example, some authors may include the name of a prominent researcher (or researchers) in the author list in order to impress editors and reviewers and acknowledge moral and financial support [39].

In areas that involve a teamwork type of association, where there may be hundreds, and sometimes even thousands, of authors per paper, papers that are co-authored by a large number of authors are often referred to as having hyper-authorship [40]. Incidents of hyper-authorship have been on the rise [41]. This issue becomes complicated because there is no way to know what the contribution of each author was. Have they all contributed equally? How many of the authors have actually sat down to co-write the paper, and how many have contributed through lab work? These difficult questions cannot be answered just by looking at the author list.

Researchers, in several cases, duly 'acknowledge' individuals who provide significant assistance to the paper, commonly referred to as sub-authorship. Acknowledgements have gradually established themselves as a constitutive element of academic writing that indicates its changing socio-cognitive structure and work practices [42]. Cognitive partnering in the research world is now common, which is reflected also in the number of co-authorships and sub-authorships [43]. However, at times, both authorship and sub-authorship could still fail to provide a full picture of collaboration. For example, Laudel [44] interviewed scientists who were co-authors, and those who were cited in 
acknowledgements, on the content and reward of collaboration. He found that a vast proportion (approximately $50 \%$ ) of collaborators were unreported through formal communication channels.

\section{The Complexity in Co-Authorship Attribution Continues, and There Are Recommendations}

Most fields now follow an order of authorship based on the significance of contribution, in which the first author contributes the most and is subsequently followed by other authors based on their contribution. Although this is a general trend, it must however be noted that some fields, e.g., economics and mathematics [8], still follow an alphabetical order of authorship listing. However, this trend in economics is also changing to a listing of authors based on significance of contribution [45]. In some cases, authors do not follow either of these author-ordering conventions (based on significance of contribution or alphabetical), and it is considered that all authors have contributed equally to the paper. It is quite likely that authors contributing equally on the paper may have their names alphabetically listed and their 'equal contribution' mentioned either in a footnote or in a section at the end of the article. Nonetheless, it is still hard to detect or assume equal contribution due to the diversity in study or experimentation stages.

Bozeman and Youtie [46] surveyed U.S.-based researchers in 14 disciplines and found that there was no consensus on who deserved to be on the author list, and the main determinants of outcome may be power dynamics, field characteristics, work culture, and the self-imposed norms of teams. In addition, established guidelines are often disregarded, and there is always a need for more explicit guidelines [47]. In another study, Shen [48] learned that, in provincial universities in China, co-authorship attribution is given based on 'long-term contributions', regardless of them being scientific or not.

Birnholtz [49] interviewed physicists (physicists generally work in large teams) and discovered that authors are grappling with what it means to be an 'author'. Due to the complexities involved with the ethical implementation of co-authorship attributes, some studies have suggested recommendations on how to address the situation. Cronin [40], for example, suggested that authors be replaced by the list of contributors and recorded in the paper unambiguously. A few studies have gone beyond the use of quantitative analytic techniques, supplementing them with qualitative methods of survey research by directly asking the co-authors of papers to indicate their real nature of contribution [50]. Jennings and El-adaway [51] recommend training on co-authorship ethical standards, documentation (formal contracts), and administrative norms. However, since co-authorship among researchers is still largely a social phenomenon, it remains to be seen how much aspects such as formal contracts and administrative norms can be adhered to. However, another recommendation has come from Smith and Master [52], who developed a five-step series of best practices for author distribution in multidisciplinary research. Several journals (i.e., PLOSOne, PNAS) now have a policy requiring a declaration of the aspects or specific roles to which each author has contributed. This obviously throws some formality into documenting what an author in the paper has contributed, but it still remains covered with obscurity. The reason is that, the same as with honorary authorship, even a declaration of the quantum of an author attribution can be manipulated.

Brand et al. [53] have proposed a contributor role taxonomy ('CRediT') to assign contributions to authors of a research paper. The authors suggest that since credit and responsibility cannot be evaluated unless authors explicitly disclose their contribution to the readers, there is a need for standardised co-ordination with respect to co-authors' contribution to a published paper. CRediT recommends that all contributors be listed, irrespective of whether they are part of the author list or not. As a contributor could be assigned multiple roles and multiple roles could be assigned to a single contributor, the system has a provision to segregate contributors as 'lead', 'equal', or 'supporting' to signify the degree of contribution. The taxonomy consists of 14 diverse roles-from Conceptualization and Data Curation to Supervision and Funding acquisition-and the effort is now to implement Credit in article tags. McNutt et al. [54] have recommended the use of the CRediT taxonomy for the attribution of author or contributor roles and consider this to be the best method currently available 
for incorporating contributions into journal metadata. A number of publications, including CELL and PLOS, now suggest the use of this taxonomy. About $17 \%$ of total publications in CELL press research papers in 2016 had used the CRediT taxonomy for author contributions. However, there remains an issue with authors' awareness of the CRediT taxonomy. A survey of 147 corresponding authors in Cell Reports for papers published in 2017 found that 73\% had not used CRediT, with 63\% reporting to be 'not aware of the option' [55]. Fourteen percent of the respondents still preferred the use of a different method of author contributions.

\section{Concluding Thoughts}

As co-authorship is a common approach to studying research collaboration at micro, meso, and macro levels, it has become crucial that only authors who have contributed significantly occupy a place in papers' author lists. Otherwise, the entire evaluation of research collaboration risks being in jeopardy. This also means that those who deserve to be on the author list should never be denied this professional recognition. Moreover, because authorship in a research article presents a reward system in terms of career promotion, tenure, performance reviews, and other incentives, there has to be an effective mechanism so that those undeserving are denied from taking undue benefit. Undoubtedly, co-authorship in scholarly papers has benefits-it, among scores of other things, helps authors to share resources and expertise and divide their work-yet co-authorship has, at the same time, given rise to several unethical practices, the chief among which, perhaps, is honorary authorship. Although bodies such as the APA and ICJME have strict guidelines, they are easily subverted.

There are several ways in which authorship issues-i.e., who should be on the paper as author and who should not and the order of authorship_could be solved. The members of a project need to discuss authorship at the very beginning of the project and detail the quantum of contribution and whether it qualifies for a significant contribution per the guidelines of the ICMJE or APA or any other recognized international committee (i.e., COPE). For example, the lead or principal author may decide who should be on the author list or cited in the acknowledgement section and who should not be in any of these. In general, whomever does not qualify for authorship may qualify for acknowledgement (i.e., someone acquiring data, providing a piece of useful advice, or someone giving out samples). However, as this examination of ethical concerns in this essay shows, one still needs to bear in mind that, no matter how articulate the rules and guidelines are, they cannot cover all the contingencies. Academia continues to grapple with the conundrum of co-authorship attribution.

Author Contributions: S.K. was the sole contributor to this article.

Funding: This research received no external funding.

Conflicts of Interest: The author declares no conflict of interest.

\section{References}

1. Sonnenwald, D.H. Scientific collaboration. Annu. Rev. Inf. Sci. Technol. 2008, 41, 643-681. [CrossRef]

2. Price, D.S. Big Science, Little Science; Columbia University: New York, NY, USA, 1963.

3. Luukkonen, T.; Persson, O.; Sivertsen, G. Understanding patterns of international scientific collaboration. Sci. Technol. Hum. Values 1992, 17, 101-126. [CrossRef]

4. Nalimov, V.; Mulchenko, B. Scientometrics; Nauka: Moscow, Russia, 1969.

5. Hood, W.W.; Wilson, C.S. The literature of bibliometrics, scientometrics, and informetrics. Scientometrics 2001, 52, 291-314. [CrossRef]

6. Price, D.S.; Weber, L. Science since babylon. Phys. Today 1961, 14, 46. [CrossRef]

7. Price, D.S. Networks of scientific papers. Science 1965, 149, 510-515. [CrossRef] [PubMed]

8. Smith, E. A theoretical foundation for the ethical distribution of authorship in multidisciplinary publications. Kennedy Inst. Ethics J. 2017, 27, 371-411. [CrossRef] [PubMed]

9. Grossman, J.W. The evolution of the mathematical research collaboration graph. Congr. Numerantium 2002, 158, 201-212. 
10. Gonzalez-Alcaide, G.; Park, J.; Huamani, C.; Gascon, J.; Ramos, J.M. Scientific authorships and collaboration network analysis on chagas disease: Papers indexed in pubmed (1940-2009). Rev. Inst. Med. Trop. Sao Paulo 2012, 54, 219-228. [CrossRef] [PubMed]

11. Miro, O.; de la Iglesia, M.A.V.; Pallas, R.M.C.; Burillo-Putze, G.; Julian, A.; Sanchez, F.J.M. Productivity of spanish emergency physicians in the 5-year periods from 2005 to 2009 and 2000-2004. Emergencias 2012, 24, 164-174.

12. Sooryamoorthy, R. Collaboration in south african engineering research. S. Afr. J. Ind. Eng. 2011, 22, 18-26. [CrossRef]

13. Moody, J. The structure of a social science collaboration network: Disciplinary cohesion from 1963 to 1999. Am. Sociol. Rev. 2004, 69, 213-238. [CrossRef]

14. Henriksen, D. The rise in co-authorship in the social sciences (1980-2013). Scientometrics 2016, 107, 455-476. [CrossRef]

15. Subramanyam, K. Bibliometric studies of research collaboration: A review. J. Inf. Sci. 1983, 6, 33-38. [CrossRef]

16. Sonnenwald, D.H. Expectations for a Scientific Collaboratory: A Case Study; ACM: Tallahassee, FL, USA, 2003; pp. 68-74.

17. Beaver, D.B. Reflections on scientific collaboration, (and its study): Past, present, and future. Scientometrics 2001, 52, 365-377. [CrossRef]

18. Beaver, D.B.; Rosen, R. Studies in scientific collaboration. Scientometrics 1978, 1, 65-84. [CrossRef]

19. Katz, J.S.; Martin, B.R. What is research collaboration? Res. Policy 1997, 26, 1-18. [CrossRef]

20. Ponomariov, B.; Boardman, C. What is co-authorship? Scientometrics 2016, 109, 1939-1963. [CrossRef]

21. Heffner, A.G. Funded research, multiple authorship, and subauthorship collaboration in four disciplines. Scientometrics 1981, 3, 5-12. [CrossRef]

22. Kuhn, T.S. The Structure of Scientific Revolutions; University of Chicago Press: Chicago, IL, USA, 1996; Volume 2.

23. Price, D.S.; Beaver, D.B. Collaboration in an invisible college. Am. Psychol. 1966, 21, 1011. [CrossRef] [PubMed]

24. Leydesdorff, L. The Challenge of Scientometrics: The Development, Measurement, and Self-Organization of Scientific Communications; Universal-Publishers: Irvine, CA, USA, 2001.

25. Garg, K.C.; Padhi, P. A study of collaboration in laser science and technology. Scientometrics 2001, 51, 415-427. [CrossRef]

26. Garfield, E. Is citation analysis a legitimate evaluation tool-Reply. Scientometrics 1980, 2, 92-94.

27. APA. Ethical Principles of Psychologists and Code of Conduct. Available online: http://www.apa.org/ ethics/code/ (accessed on 7 May 2018).

28. Hwang, S.S.; Song, H.H.; Baik, J.H.; Jung, S.L.; Park, S.H.; Choi, K.H.; Park, Y.H. Researcher contributions and fulfillment of icmje authorship criteria: Analysis of author contribution lists in research articles with multiple authors published in radiology. Radiology 2003, 226, 16-23. [CrossRef] [PubMed]

29. Zaki, S.A.; Taqi, S.A.; Sami, L.B.; Nilofer, A.R. Ethical guidelines on authorship. Indian J. Dent. Res. 2012, 23, 292. [CrossRef] [PubMed]

30. ICMJE. Defining the Role of Authors and Contributors. Available online: http://www.icmje.org/ recommendations/browse/roles-and-responsibilities / defining-the-role-of-authors-and-contributors. html (accessed on 10 June 2018).

31. Abbott, A. Dispute over first authorship lands researchers in dock. Nature 2002, 419, 4. [CrossRef] [PubMed]

32. Zuckerman, H. Patterns of name ordering among authors of scientific papers: A study of social symbolism and its ambiguity. Am. J. Sociol. 1968, 74, 276-291. [CrossRef]

33. Jabbehdari, S.; Walsh, J.P. Authorship norms and project structures in science. Sci. Technol. Hum. Values 2017, 42, 872-900. [CrossRef]

34. Hagstrom, W.O. The Scientific Community; Basic Books: New York, NY, USA, 1965.

35. Flanagin, A.; Carey, L.A.; Fontanarosa, P.B.; Phillips, S.G.; Pace, B.P.; Lundberg, G.D.; Rennie, D. Prevalence of articles with honorary authors and ghost authors in peer-reviewed medical journals. JAMA J. Am. Med. Assoc. 1998, 280, 222-224. [CrossRef]

36. Mowatt, G.; Shirran, L.; Grimshaw, J.J.M.; Rennie, D.; Flanagin, A.; Yank, V.; MacLennan, G.; Gotzsche, P.C.; Bero, L.A. Prevalence of honorary and ghost authorship in cochrane reviews. JAMA J. Am. Med. Assoc. 2002, 287, 2769-2771. [CrossRef] 
37. Wislar, J.S.; Flanagin, A.; Fontanarosa, P.B.; DeAngelis, C.D. Honorary and ghost authorship in high impact biomedical journals: A cross sectional survey. Br. Med. J. 2011, 343, d6128. [CrossRef] [PubMed]

38. Marusic, A.; Bosnjak, L.; Jeroncic, A. A systematic review of research on the meaning, ethics and practices of authorship across scholarly disciplines. PLOS ONE 2011, 6, e23477. [CrossRef] [PubMed]

39. Riesenberg, D.; Lundberg, G.D. The order of authorship: Who's on first? JAMA J. Am. Med. Assoc. 1990, 264, 1857. [CrossRef]

40. Cronin, B. Hyperauthorship: A postmodern perversion or evidence of a structural shift in scholarly communication practices? J. Am. Soc. Inf. Sci. Technol. 2001, 52, 558-569. [CrossRef]

41. Knudson, D. Twenty-year trends of authorship and sampling in applied biomechanics research. Percept. Mot. Skills 2012, 114, 16-20. [CrossRef] [PubMed]

42. Cronin, B.; Shaw, D.; La Barre, K. A cast of thousands: Coauthorship and subauthorship collaboration in the 20th century as manifested in the scholarly journal literature of psychology and philosophy. J. Am. Soc. Inf. Sci. Technol. 2003, 54, 855-871. [CrossRef]

43. Cronin, B. Bowling alone together: Academic writing as distributed cognition. J. Am. Soc. Inf. Sci. Technol. 2004, 55, 557-560. [CrossRef]

44. Laudel, G. What do we measure by co-authorships? Res. Eval. 2002, 11, 3-15. [CrossRef]

45. Kumar, S.; Ratnavelu, K. Perceptions of scholars in the field of economics on co-authorship associations: Evidence from an international survey. PLoS ONE 2016, 11, e0157633. [CrossRef] [PubMed]

46. Bozeman, B.; Youtie, J. Trouble in paradise: Problems in academic research co-authoring. Sci. Eng. Ethics 2016, 22, 1717-1743. [CrossRef] [PubMed]

47. Cutas, D.; Shaw, D. Writers blocked: On the wrongs of research co-authorship and some possible strategies for improvement. Sci. Eng. Ethics 2015, 21, 1315-1329. [CrossRef] [PubMed]

48. Shen, S.X. Negotiating authorship in chinese universities: How organizations shape cycles of credit in science. Sci. Technol. Hum. Values 2016, 41, 660-685. [CrossRef]

49. Birnholtz, J.P. What does it mean to be an author? The intersection of credit, contribution, and collaboration in science. J. Am. Soc. Inf. Sci. Technol. 2006, 57, 1758-1770. [CrossRef]

50. Pepe, A.; Rodriguez, M.A. Collaboration in sensor network research: An in-depth longitudinal analysis of assortative mixing patterns. Scientometrics 2010, 84, 687-701. [CrossRef] [PubMed]

51. Jennings, M.M.; El-adaway, I.H. Ethical issues in multiple-authored and mentor-supervised publications. J. Prof. Issues Eng. Educ. Pract. 2012, 138, 37-47. [CrossRef]

52. Smith, E.; Master, Z. Best practice to order authors in multi/interdisciplinary health sciences research publications. Account. Res. 2017, 24, 243-267. [CrossRef] [PubMed]

53. Brand, A.; Allen, L.; Altman, M.; Hlava, M.; Scott, J. Beyond authorship: Attribution, contribution, collaboration, and credit. Learn. Publ. 2015, 28, 151-155. [CrossRef]

54. McNutt, M.K.; Bradford, M.; Drazen, J.M.; Hanson, B.; Howard, B.; Jamieson, K.H.; Kiermer, V.; Marcus, E.; Pope, B.K.; Schekman, R. Transparency in authors' contributions and responsibilities to promote integrity in scientific publication. Proc. Natl. Acad. Sci. USA 2018, 115, 2557-2560. [CrossRef] [PubMed]

55. Harp, G. Credit Taxonomy of Contributor Roles: Implementation at Cell Press. Available online: https:/ / www.inera.com/customers/XUG-2017-CellPress-CRediT.pdf (accessed on 26 July 2018).

(C) 2018 by the author. Licensee MDPI, Basel, Switzerland. This article is an open access article distributed under the terms and conditions of the Creative Commons Attribution (CC BY) license (http://creativecommons.org/licenses/by/4.0/). 